\title{
HUMAN FACTORS ENGINEERING PROGRAM DEVELOPMENT AND USER INVOLVEMENT IN DESIGN OF AUTOMATIC TRAM
}

\author{
Hanna Koskinen, Susanna Aromaa and Vladimir Goriachev \\ VTT Technical Research Centre of Finland Ltd. Tekniikantie 21, PL1000, 02044 VTT, Finland
}

\begin{abstract}
Our transport system is currently undergoing fundamental change due to increasing use of automation. New automation solutions are introduced in all sectors of transportation, for example automated metros and autonomous ships are in the visions of technology developers. There are many reasons for this ongoing trend of higher use of automation such as demands for sustainability and efficiency to mention some. In this paper, we present a research and development effort aiming at introducing an automatic tram, that is to say SmartTram. In particular, we concentrate on how the changing role of human (as driver, passenger and member of other user groups) is acknowledged in the design of a new automatic tram. For this reason, we present a human factors engineering program for automated trams. The special focus is on how the relevant user groups may be involved in design within the defined program. This approach can be utilized also in other sectors when increasing automation.
\end{abstract}

\section{KEYWORDS}

Public Transport, Automatic Tram, Human Factors Engineering, User Involvement, Design

\section{INTRODUCTION}

There is a worldwide initiative to increase use of automation solutions in transport systems and enable new kind of mobility services that are in the center of the smart city concepts. Even though the research and development of automated passenger cars may have gain more attention (Cohen et al., 2017; Kyriakidis et al., 2019; Merat \& Jamson, 2009) the same trend of increasing level of automation (LoA) impacts on all other sectors of transportation (e.g., public transportation and transportation of cargo) (Beiker, 2014; Karvonen et al., 2011; Wahlström et al., 2016). In this paper, our focus is on public transportation and in particular developing automatic solutions for trams. In the context of public transportation, some automatic solutions are already introduced. For example, in many cities there are at least some individual metro 
IADIS International Journal on Computer Science and Information Systems

lines that are fully automated and operate without human drivers. However, the design task, that is to say, the development of automatic tram, is challenging because the tram needs to operate in an open infrastructure opposite to the closed-rail systems that most of the introduced automatic transport systems such as the abovementioned automated-metros has been earlier. Moreover, apart from few exceptions, not many reference cases about automatic trams may be found (see e.g., Hofmann, 2020). The urban city environments that the conventional trams often operate are, from the automation design point of view, the most challenging ones. Even the automatic driving assistants that are currently planned and introduced in highway-driving context presents moderate challenge if compared to the automatic driving in lively downtown streets. In these urban environments, detecting reliable variety of objects (e.g., pedestrians and other vulnerable road users [VRU]) and other aspects of the driving environment (e.g., weather and lighting conditions or traffic work sites) demands advanced sensor networks and high connectivity. Thus, many technical innovations and solutions are still required in order to realize fully automatized transportation.

When considered from the operation and human point of view, the automatic tram will change the tram driver's work substantially. In the automatized tram, the tram driver will no longer be expected handling all the operative level driving tasks (e.g., driving by sight, controlling driving speed and stopping at tram stops). Consequently, the main task of the tram driver shifts toward supervising the automatic driving system. Thus, even with the increasing levels of automation, the human operator will be needed at least to supervise and monitor that the system operates as intended. In some concept of operations (ConOps), the human driver may also be expected to intervene in the operation in case of an emergency or some complex driving situation (e.g., handling changing to a detour or passing a traffic work site). Regardless the automation concept, the human tram diver will be likely involved in the operation of the tram also in the future. From the passengers' point of view, the automatic tram is a notable change, as well. There may be emotional issues and experiences such as if the functioning of the automatic tram can be trusted (Karvonen et al., 2011) and if people are willing to use automatic trams. In addition, there may be uncertainty how to behave and use the tram service if there is no human driver to ask help in unclear situations. Moreover, in public transportation it is common that some troublemaker or louts make the other passengers feel insecure and this feeling may further grow if there is no human driver in the tram. When considering the other road users, number of studies have been investigating the interaction of the pedestrians and other VRUs with the automatic vehicles (Hulse et al., 2018; Parkin et al., 2016; Rasouli $\&$ Tsotsos, 2018). In these studies, different visualization and signaling concepts have been suggested and explored in order to make sure that the intentions of the automatic vehicle is communicated appropriately to the other road users and the traffic safety is maintained. In addition, there are also other possible stakeholders to consider in the design of automatic trams, for example, how the content of the work and the knowledge requirements for the maintenance technicians will change. Due to several user groups with varying needs and expectations, driving a tram and the human interaction with the automated tram will remain as an important human factors issue that should be taken under careful investigation in design and development of these systems.

There are a lot of research indicating that applying the principles of human-centered design and user involvement enable better acknowledging the user needs and thus leading developing products that are more successful (Kujala, 2003; Bødker \& Pekkola, 2010). Unfortunately, experiences from practice show that these benefits are not often achieved because the industry 
lacks knowledge and proper methods about how to appropriate deal with the human and social aspects in design (Bano \& Zowghi, 2015).

In this paper, we introduce the human factors engineering (HFE) program including iterative evaluation of future solution that have been developed for the SmartTram project in order to acknowledge appropriately the human and social aspect in the design of the automatic tram. We first discuss the importance of developing proper HFE program in safety-critical design projects. Within the HFE program, participatory processes and involvement of relevant user groups should be considered so that contextually grounded and informed design decisions can be made. After providing general view, we introduce the specific HF activities and points of user interaction planned regarding the SmartTram project. A particular emphasis has been put on laying out the iterative verification and validation $(\mathrm{V} \& \mathrm{~V})$ plan and the related simulator and training facilities, which play an important role in interacting with the future users. We conclude by discussing the challenges of implementing HFE program and allowing the users' valuable operative knowledge to inform design.

\section{HUMAN FACTORS ENGINEERING IN SAFETY-CRITICAL DESIGN PROJECTS}

A systematic approach and human factors practices are needed in the design of safety-critical systems such as control rooms of nuclear power plants, cockpits of aircrafts and operating theatres in hospitals where many technical but also social and organizational aspects need to be seamlessly integrated. In addition, maintaining holistic and life cycle perspective are also important in order to reach a proper socio-technical understanding of the design task.

\subsection{Organizing Human Factors Engineering Activities}

It has been suggested in the literature, that at least the following list of HF activities should be included in design of complex systems: screening, management and planning, operating experience (OE) review, development of ConOps, function allocation and analysis, task analysis, human reliability analysis, personnel selection, training and qualifications, system design and development, design of maintenance activities, $\mathrm{V} \& \mathrm{~V}$, and commissioning and in-time operation monitoring (EPRI, 2004; NUREG-0711, 2012). All these HFE activities should be carried out in a coordinated manner and at the same time, there should be a continuous, effective and timely dialogue between the human factors representatives and the other engineering specialists working in the project (e.g., Hugo, 2000). This is not a straightforward task to do. Consequently, the importance of HFE integration in complex engineering projects is widely recognized. The benefits of HFE integration may be, for example, that the problems can be avoided or mitigated and, design relevant information and feedback from the evaluations can be more effectively fed back to the design. Thus, drafting a more formal HFE program within which all the HF activities, their deliverables and main interactions with the other design parties in a project are described is one way to address the integration problem and create a base for high quality HFE practices. The HFE program should cover all the phases of the design process from the initial clarification and analysis phase to the final implementation of the system. Because of the different starting points and contextual circumstances in different design projects it is expected that the HFE program will need to be tailored and customized individually to each 
IADIS International Journal on Computer Science and Information Systems

project even though the basic structure of the HFE program would be much alike. Based on abovementioned requirements, a general structure for HFE program in safety-critical system design is outlined in Table 1.

Table 1. General outline of HFE program for safety-critical system design

\begin{tabular}{|c|c|c|}
\hline Input & Design process & Output \\
\hline \multirow{4}{*}{$\begin{array}{l}\text { - Need for } \\
\text { change (e.g.,) } \\
\text { - Existing } \\
\text { concepts) } \\
\text { - Operational } \\
\text { experience }\end{array}$} & \multirow{4}{*}{$\begin{array}{l}\text { Initial clarification } \\
\text { and analysis } \\
\text { Impact, needs and } \\
\text { constraints, HFE } \\
\text { goals }\end{array}$} & - HF input to project plan \\
\hline & & - HFE program/ activities \\
\hline & & $\begin{array}{r}\text { (i.e., tasks, schedule and } \\
\text { resources) }\end{array}$ \\
\hline & & $\begin{array}{r}\text { - Preliminary evaluation } \\
\text { schema }\end{array}$ \\
\hline \multirow{4}{*}{$\begin{array}{l}\text { - Operating } \\
\text { environment description } \\
\text { - User and safety } \\
\text { requirements } \\
\text { - Standards }\end{array}$} & \multirow{4}{*}{$\begin{array}{l}\text { Requirements and } \\
\text { concept design } \\
\text { Concept of } \\
\text { operation, Task } \\
\text { analysis, User } \\
\text { requirements }\end{array}$} & $\begin{array}{l}\bullet \text { Concept (documenting } \\
\text { ConOps, level of automation, }\end{array}$ \\
\hline & & user-system interaction) \\
\hline & & - Project-specific requirements \\
\hline & & $\begin{array}{r}\text { - HSI style guide (e.g., design } \\
\text { principles, layout, } \\
\text { color-coding, alarms etc.) }\end{array}$ \\
\hline \multirow{2}{*}{$\begin{array}{l}\text { - I\&C architectures } \\
\text { - Standards }\end{array}$} & $\begin{array}{c}\text { Detail/integrated } \\
\text { design }\end{array}$ & \multirow[t]{2}{*}{$\begin{array}{l}\text { - Physical work environment } \\
\text { and user interface solution }\end{array}$} \\
\hline & $\begin{array}{l}\text { User interface, } \\
\text { training design }\end{array}$ & \\
\hline \multirow{3}{*}{$\begin{array}{l}\text { - V\&V plan } \\
\text { - Standards }\end{array}$} & $\begin{array}{c}\text { Verification \& } \\
\text { validation }(V \& V)\end{array}$ & \multirow{3}{*}{$\begin{array}{r}-\mathrm{V} \& \mathrm{~V} \text { record (e.g., identified } \\
\text { human engineering } \\
\text { discrepancies and design } \\
\text { feedback, further design } \\
\text { iterations) }\end{array}$} \\
\hline & Simulations, field & \\
\hline & $\begin{array}{l}\text { tests, Validation } \\
\text { tests }\end{array}$ & \\
\hline Training curriculum & $\begin{array}{l}\text { Implementation \& } \\
\text { commissioning }\end{array}$ & $\begin{array}{r}\text { - Accumulated evaluation } \\
\text { record }\end{array}$ \\
\hline
\end{tabular}

\subsection{Involvement of Relevant user Groups}

Within human factors engineering, the human-centered design and participatory processes are suggested to be one way to acknowledge human and social issues in safety-critical system design. Active involvement of relevant user groups in design has been proven to be valuable in improving the different aspects of the design solution (Bødker \& Pekkola, 2010). For example, through user involvement the ambiguity about the design task may be resolved and thus produce solutions that better fit the preferences and needs of the users and that are generally more valued.

Even though the benefits of active user involvement in design seem evident, number of studies indicate difficulties and failures in applying the principles of participatory design (Bano \& Zowghi, 2015; Kujala, 2003). For example, in the context of medical device design (Money et al., 2011) conducted in-depth interviews with 11 medical device manufacturers about their beliefs and attitudes towards user involvement in their product development processes. The 
interview study revealed that the medical device manufacturers had unclear perception of who the user is, and they lacked methodical knowledge about how to incorporate human factors methods in their product development processes and what kind of contribution the users could provide. Moreover, they perceived the activities related to the user involvement time-consuming and laborious, and the manufacturers tended to believe that the information provided by the senior medical experts (e.g., experienced medical doctors) would be the most reliable source of user information even though the senior experts would not be the main users of the device in their daily work. It was concluded that methods should be developed in order to realize and better fit the participatory processes in day-to-day product development practices of medical device manufacturers. Within another study in a highly regulated domain of offshore oil and gas industry, described by (Balfour et al., 2012) reports a survey conducted among the human factors engineering consults and that aimed at investigate how user involvement in design projects has been realized in the petroleum field. Many challenges were identified in the study. For example, even though user participation is regulated and mandatory throughout the design process the stakeholders perceive it as costly and many times also annoyance that was just seen to slow down the development process. Availability of representatives of relevant user groups was a more practical problem as the offshore employees work two weeks straight and then have four weeks of free, which means that it is difficult to build up any continuity on the user involvement. It was also found out that the user representatives did not always have a clear mandate from all the other users which caused conflicts throughout the process and when the new design solution was finally introduced and implemented into use. It was suggested that documenting and presenting real-life case that clearly would illustrate and make tangible the benefits of the user involvement could aid the different design parties to understand and value the human factors work done with the users.

In order to avoid many of the abovementioned problems and issues in user involvement, incorporating a plan for points of user interaction within the HFE program is proposed. The plan should take a stand on at least the type of users, the form of involvement, the specific methods and other resources needed for the user interaction. In other words, the planning of design activities and user involvement should happen at all levels, that is, at the organization, process and product level in order to fulfill the demands of systematic and fully-fledged participatory design process. In safety-critical system design context, careful documentation of not only the outcome (i.e., end product) but also the development process is often required. Thus, introducing a proper HFE program, which includes also a detailed account of the HF activities aiming at involving relevant user groups, may guarantee for one's part a high quality of the product development process.

\section{HUMAN FACTORS ENGINEERING IN SMARTTRAM PROJECT}

In demonstrating the benefits of preparing a HFE program, we turn to a research project called SmartTram. The SmartTram project is part of a joint Finnish living lab activity and initiative that aims at finding more sustainable and user-friendly solutions for public transportation. The Technical Research Centre of Finland VTT self-funded SmartTram project is a research-oriented project that aims to support the industry projects and collect the different ecosystem partners to discuss and build the smart tram concept. In the SmartTram project, a 
multidisciplinary team of researchers collaborates in developing different aspects, both the technical as well as the service infrastructure, needed for realizing the automatic tram solutions. The social and human aspect is important in the SmartTram project as the automatic trams are expected to operate in our everyday living environment, often at the busy downtown areas. Thus, the development of automatic tram should be sensitive to how it is perceived by the public not to mention the tram drivers whose work is anyway going to change radically. For that reason a HFE program and a specific plan for the iterative evaluation of the SmartTram with the particular emphasis on the experiences of different user groups was prepared and implemented as a part of the development process. In presenting the SmartTram specific HFE program, we exemplify how through active user involvement in different phases of the development project valuable contributions can be gained that may support and help directing the development of the automatic tram concept towards a successful outcome.

\subsection{Human Factors Engineering Program}

In the SmartTram project, number of engineering knowledge areas are involved in reaching agreements and finding solutions that can make the idea of the automatic tram a functional transportation service in smart city. From the HFE program point of view it is necessary to broke down the project into actionable steps that can be resourced and that successfulness evaluated at scheduled milestones. At the beginning of the design process, there is a need to analyze the problem space and conduct research in order to be able to more precise define the design task. Later on, the design idea gets more and more matured form and develops from an abstract concept to a concrete integrated solution. Consequently, the planned HF activities within the SmartTram project are variety.

In the Table 2, the HFE program and the planned HF activities in the SmartTram project has been summarized. The HF activities are the main responsibility of HFE specialists working in the SmartTram project but in realizing them close collaboration with the other engineering disciplines as well as other relevant interest groups such as city representatives are needed.

Table 2. A HFE program and the planned points of user interaction (PoUI) in the SmartTram project. PoUIs are marked with green italic font and from operation and service point of view. SUC = Systems Usability Case, ConOps = Concept of Operations

\begin{tabular}{|c|c|c|}
\hline Input & Design process & Output \\
\hline \multirow{4}{*}{$\begin{array}{l}\text { - Need for change (e.g., } \\
\text { growing amount of passengers, } \\
\text { sustainable and environmentally } \\
\text { friendly public transport } \\
\text { solutions) } \\
\text { - Existing concepts (e.g., proofs } \\
\text { of concept, level of automation) }\end{array}$} & $\begin{array}{l}\text { Initial clarification and analysis } \\
\text { (impact, needs and constraints, } \\
\text { HFE goals) }\end{array}$ & $\begin{array}{l}\text { - HF input to project } \\
\text { plan (identification of } \\
\text { relevant user groups) }\end{array}$ \\
\hline & $\underline{P o U I}$ & \multirow{4}{*}{$\begin{array}{l}\text { - HFE program/ } \\
\text { activities (i.e., tasks, } \\
\text { schedule and resources) } \\
\text { - Preliminary } \\
\text { evaluation schema (i.e., } \\
\text { SUC, subsystems and } \\
\text { integrated system } \\
\text { validation) }\end{array}$} \\
\hline & Operation: Tram driver \& traffic & \\
\hline & control centre personnel & \\
\hline $\begin{array}{l}\text { - Operational experience (other } \\
\text { automated traffic solutions e.g., } \\
\text { metro) }\end{array}$ & $\begin{array}{l}\text { Service: passenger \& road users } \\
\text { (surveys, interviews) }\end{array}$ & \\
\hline
\end{tabular}




\begin{tabular}{|c|c|c|}
\hline Input & Design process & Output \\
\hline $\begin{array}{l}\text { - Operating environment } \\
\text { description } \\
\text { - User and safety requirements } \\
\text { - Standards }\end{array}$ & $\begin{array}{c}\text { Requirements and concept } \\
\text { design (ConOps, task analysis, } \\
\text { user requirements) } \\
\underline{\text { PoUI }} \\
\text { Operation: Field observation. } \\
\text { Explorative prototyping and } \\
\text { testing with tram drivers (field, } \\
\text { simulator) } \\
\text { Service: Passenger \& road users } \\
\text { (e.g., focus groups) }\end{array}$ & $\begin{array}{l}\text { - SmartTram concept } \\
\text { (level of automation, } \\
\text { documentation of } \\
\text { ConOps, user interaction) } \\
\text { - Project requirement set } \\
\text { - HSI style guide (e.g. } \\
\text { main design principles, } \\
\text { HSI guidance on layout, } \\
\text { alarms, navigation, } \\
\text { color-coding etc.) }\end{array}$ \\
\hline $\begin{array}{l}\text { - I\&C architectures } \\
\text { - Standards }\end{array}$ & $\begin{array}{l}\text { Detail/integrated design (User } \\
\text { interface, training design) } \\
\qquad \underline{P o U I} \\
\text { Operation: Iterative development } \\
\text { of solutions with tram drivers } \\
\text { (simulator, workshops) } \\
\text { Service: User testing with } \\
\text { passenger \& road users } \\
\text { (simulator, workshops) }\end{array}$ & $\begin{array}{l}\text { - Tram user interface and } \\
\text { interior solution }\end{array}$ \\
\hline $\begin{array}{l}\text { - V\&V plan (e.g., users groups, } \\
\text { scenarios, acceptance criteria) } \\
\text { - Standards }\end{array}$ & $\begin{array}{l}\text { Verification \& validation } \\
\text { (Simulations, Validation tests) } \\
\qquad \underline{\text { PoUI }} \\
\text { Operation: SSV and ISV tram } \\
\text { drivers (simulator) } \\
\text { Service: ISV passenger \& road } \\
\text { users (simulator) }\end{array}$ & $\begin{array}{l}\text { - V\&V record (identified } \\
\text { human engineering } \\
\text { discrepancies, design } \\
\text { feedback, decisions on } \\
\text { further design iterations) }\end{array}$ \\
\hline - Training curriculum & $\begin{array}{l}\text { Implementation, commissioning } \\
\qquad \underline{P o U \boldsymbol{I}} \\
\text { Operation: Operating experience } \\
\text { of tram drivers (Field) } \\
\text { Service: Customer experience of } \\
\text { passenger \& road users (Field) }\end{array}$ & $\begin{array}{l}\text { - Accumulated evaluation } \\
\text { record (document early } \\
\text { operating experiences) }\end{array}$ \\
\hline
\end{tabular}

\subsubsection{Initial Clarification and Analysis Phase of SmartTram}

Currently, the project is in its Initial clarification and analysis phase, that is to say, a lot of analytical research work is carried out. For example, alternatives for the SmartTram technical platform are investigated. The design task of automatic tram is challenging, as the tram should operate in an open infrastructure (i.e., urban city environment) in which also number of other road users are encountered. One central question in the SmartTram project is the suitable level of automation (LoA) (SAE, 2018) that is an integral part of defining the concept of operations (ConOps). How much or little human intervention is needed and what is the role of human driver in the operation of the future SmartTram. This design decision if anything affects the core tasks 
IADIS International Journal on Computer Science and Information Systems

(i.e., the contextually meaningful content of the work) (Norros, 2004) of the tram drivers. With the high levels of automation, the tram driver will no longer be expected handling all the driving tasks at operative level such as driving by sight, controlling the driving speed or stopping at tram stop. In this high-level automation scenario, the main task of the dram driver is expected to shift towards supervising the automatic driving system, that is, away from directly operative tasks to tactical level tasks. However, the SmartTram ConOps could also be something different yet being a design decision that the tram drivers' experiences and operative knowledge could inform and contribute substantially. Therefore, in the Initial clarification and analysis phase, it is essential to conduct interviews with the tram drivers and potentially with other operative personnel. Benchmarking the existing public transport concepts (e.g., what kind of human-system interaction concepts they are based on, and what are the pros and cons of those solutions) may complement the understanding of the present situation. In addition, operating experiences of similar systems are of interest in this phase. It may be that not many directly comparable solutions (i.e., automatic trams) still exist; however, operating experiences on other automatic transport and machinery may offer a valuable course of information as well. As it seems likely that the core tasks of the tram drivers will change at least to some degree from the operative driving to supervisory role benchmarking on, for example, about the existing human-system interaction concepts and type of information displays in tram driving should be conducted.

While the tram drivers are obviously one central group of users whose needs and preferences should be paid attention to in design also other essential user groups may be identified. After initial contextual analysis of the relevant user groups at least five distinct group of users were recognized of importance (see Table 3). Nowadays when systems are becoming more complex (e.g., due to their scope and size increases), and interconnected (systems of systems) there may not be just one clearly defined end user of the system but instead several and the role of those users may become increasingly blurred. Therefore, at the beginning of the project a preliminary analysis of relevant user groups is necessary even though it may be that later on some new unidentified group of users can be found like in the general practitioners' receptionist in the study on design of new electronic ordering of laboratory services reported by (Johannessen \& Ellingsen, 2008). In the case of the electronic laboratory service ordering system, the discovery of this new group of users resulted in new functionalities designed to the system that accommodated for the work of the receptionists. In the SmartTramp project, the passengers of the automatic tram are the other essential user group that should be involved in the design but other less evident may be the possible maintenance or the traffic control centre personnel and the other road users such us the pedestrians or car drivers. For example, the question of how the traffic control centre personnel may be in contact with the automatic tram in a case of an exceptional traffic situation in which the centre has a coordinating role. The information about the number and type of user groups serve as an input for planning the SmartTram project and drafting the specified HFE program (i.e., planned HF activities and points of user interaction within the project) and preliminary evaluation schema (i.e., V\&V plan). 
Table 3. A summary of the identified user groups, their potential knowledge contribution and the design artefacts in which the user knowledge may be exploited

\begin{tabular}{lll}
\multicolumn{1}{c}{ User group } & Knowledge contribution & Design artefact \\
\hline $\begin{array}{l}\text { Tram drivers (primarily } \\
\text { conventional tram drivers or if } \\
\text { access, tram drivers that has } \\
\text { experience on automatic trams) }\end{array}$ & $\begin{array}{l}\text { Knowledge on different driving situations } \\
\text { (e.g., weather conditions, interaction with } \\
\text { other road users), human-system interfaces } \\
\text { and interaction with the passengers }\end{array}$ & $\begin{array}{l}\text { ConOps, LoA, core } \\
\text { tasks, user req. } \\
\text { (driving system } \\
\text { HSI) }\end{array}$ \\
\hline $\begin{array}{l}\text { Passengers (people who uses } \\
\text { trams on a regular basis, other } \\
\text { public transport users) }\end{array}$ & $\begin{array}{l}\text { Attitudes and user experience (e.g., trust, } \\
\text { fear) on automatic trams, travelling } \\
\text { preferences and habits }\end{array}$ & $\begin{array}{l}\text { LoA, user req. } \\
\text { (cabin HSI) }\end{array}$ \\
\hline $\begin{array}{l}\text { Traffic control centre operator } \\
\text { Knowledge on traffic system monitoring } \\
\text { (overall system view) and exceptional } \\
\text { traffic situations and communication needs }\end{array}$ & $\begin{array}{l}\text { ConOps, user req. } \\
\text { (safety HSI) }\end{array}$ \\
\hline $\begin{array}{l}\text { Maintenance personnel/ } \\
\text { technician) }\end{array}$ & $\begin{array}{l}\text { Knowledge on occurrence of technical } \\
\text { issues }\end{array}$ & $\begin{array}{l}\text { user req. (service } \\
\text { panel HSI) }\end{array}$ \\
\hline $\begin{array}{l}\text { Other road users (e.g., } \\
\text { pedestrian, cyclist, car and bus } \\
\text { drivers) }\end{array}$ & $\begin{array}{l}\text { Experiences on interaction with the tram in } \\
\text { different traffic situations (awareness of } \\
\text { others intentions }\end{array}$ & $\begin{array}{l}\text { user req. (signaling } \\
\text { HSI) }\end{array}$ \\
& &
\end{tabular}

\subsubsection{Requirements and concept design phase of SmartTram}

In the Requirement and concept design phase, there is a need to start defining the SmartTram concept more precisely. Decisions about the level of automation and the human-system interaction concept should be arrived as a part of the development of the final concept of operation. In this design phase, an appropriate understanding of the human and social context of the SmartTram is especially important. The expert users typically have significant operative knowledge about the application domain, how the different tasks are performed and what are the daily work practices. Therefore, in the SmartTram project, the aim is to devote a special attention to the involvement of expert users, that is, the tram drivers in design the different solutions and testing them by means of the simulator and a series of exploratory design workshops.

\subsection{Verification and Validation Plan}

Iterative evaluation and testing is an integral part of designing complex safety-critical systems (see Figure1) and the continuous engineering paradigm that promote improvements throughout the product life cycle. Thus, the HFE evaluation schema should be considered already from the very beginning of any development project. That is also why in the SmartTram project, the V\&V plan was drafted in the first phase of the project (i.e., Initial clarifications and analysis phase in the Table 1 and 2). Typical for complex system engineering projects, like the SmartTram-project, are that they are very long and therefore the design work is often divided into several stages or manageable parts that follow each other's. A concept of subsystem validation (SSV) (Laarni et al., 2014) has been introduced to carry out successive evaluations throughout the design whenever a part of a whole get completed and ready for testing. For 
IADIS International Journal on Computer Science and Information Systems

example, a modernization of a control room may be realized in stepwise and thus the evaluation of different subsystems (e.g., normal operation and safety systems) become timely in different time windows in the project. Following the SSVs, an integrated system validation (ISV) is conducted before the commissioning phase of the new system. It is also essential that when the system is in its operative state, the operating experiences are systematically collected (i.e., system performance is continuously monitored), and used as an input for identifying further places of improvements for the system.

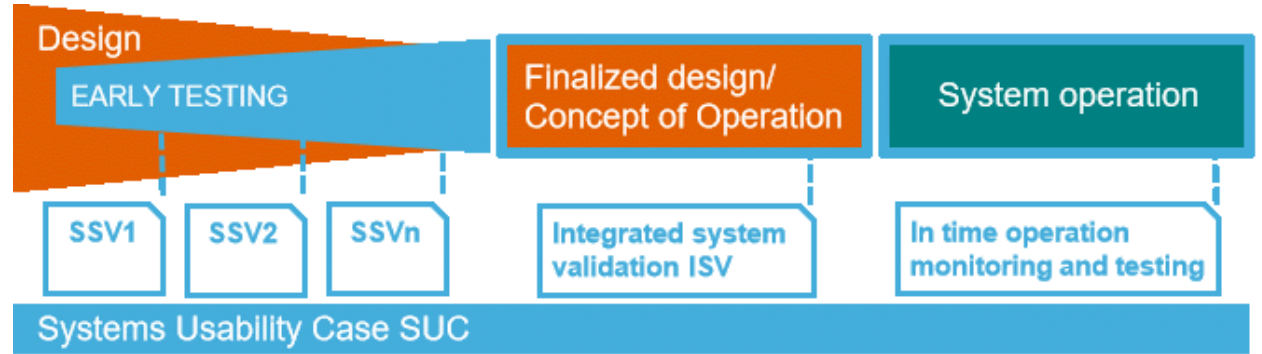

Figure 1. Iterative evaluation throughout the life cycle of a complex safety-critical system

Moreover, it is expected that a huge amount of HFE data being gathered even within one complex system engineering project and the life cycle of that system. An evaluation approach called Systems Usability Case (SUC) (Koskinen et al., 2021; Liinasuo \& Norros, 2007) has been used as a methodical starting point in the SmartTram project for managing and organizing the system evaluation. A safety case (Bishop \& Bloomfield, 1998) is required in many safety standards and therefore produced in variety safety-critical domains as a part of their normal qualification procedure. SUC approach bases on Systems Usability (SU) construct (Savioja, 2014) and the safety case thinking and it exploits the design requirements in forming the set of criteria for the HFE evaluations. The SUC approach is considered to be especially well suited to evaluation of systems that are complex and unique by their nature. The SUC is constructed from two distinct parts. In the first part of the SUC procedure, called as a goal structure, the project specific design requirements are organized thematically with regards to the more generic usability and HFE requirements and the high-level acceptance goal set for the project. Through this construction, a more specified set of acceptance criteria and the test occasions (e.g., scenarios) in which the fulfilment of the requirements may be tested are derived. Going through the design rational and the documentation helps also the HFE evaluators to become better acquainted with the system and thus be able to ask more specific and detailed questions concerning the systems usability. After constructing the goal structure, an evaluation session is realized to collect evidence. These evaluation sessions may be carried out with different type of mockups and prototypes or in more advanced simulator environments depending on the maturity of the design solution and the project phase. At early-stages, evaluations are formative by their nature (i.e., aim at produce design feedback for improvements) whereas at later stages of the development process the evaluations are more summative. In the second part of the SUC (that is proceed after the actual evaluation occasion), called as a claim structure, a reasoning process takes place. The claim structure comprises of a set of evidence, arguments and claims. Constructing the claim structure aims to create a documented body of evidence providing a valid argument of the degree of systems usability of the system under consideration (Liinasuo \& Norros, 2007). Often it is so that in the early phase (formative) evaluations the number of 
human engineering discrepancies (HEDs) indicating existence of HF issues and problems is still relatively high. Each identified HED needs to be handled individually and give an appropriate resolution. Solving one HED may require redesign whereas for other HED supplementary training of personnel may be the most effective way to handle the identified issue. When coming closer to the implementation and commissioning phase and the ISV (i.e., summative evaluation) of the system it is expected that the amount of HEDs is lower. This is because of many of the HF issues have already been able to solve and act upon earlier in the V\&V process. No critical HEDs should be existing in the system at the time of implementation. Using SUC helps to conduct the $\mathrm{V} \& \mathrm{~V}$ process in a systematic, transparent and longitudinal fashion.

In the SmartTram project, the human factors data from the different user evaluations and point of user interactions will be documented according the SUC procedure. Consequently, a well-documented design rationale and evaluation record can be achieved that is important in safety-critical system design.

\subsection{SmartTram Simulator Facility for User Testing}

One useful approach to be applied during an HFE program in a safety-critical system design is virtual reality (VR) based models and simulators. In VR, digital technology provides simulation of reality typically through visual, auditory, and haptic interfaces. By using VR simulators in the context of safety-critical system design, it is possible to immerse users to their future operating tasks in a safe environment. The VR simulators exist realized with varying technical solutions (e.g., from visualizations on a PC screen to immersive virtual environments experienced with head mounted displays) and they can be used for different purposes during the HFE program. For example, by using a VR simulator it is possible to train new tram drivers to cope with the hazard traffic situations. In general, there are several reasons contributing to VR simulators' usefulness, such as converting the abstract to the concrete (e.g., making some specific concept idea illustratively tangible) and making hands-on training possible in situations where it is still impossible to train things in the real world setting. Moreover, VR could allow cost-efficiently compare alternative options, for example, different user interface concepts and illustrations, different levels of automation or arrangements of layout in tram cockpit (if there is still need for one).

Early on in the SmartTram project, the need for a virtual environment that would allow exploring the different characteristics of the SmartTram system was recognized. Consequently, a VR based simulator was created for the SmartTram system (see Figure 2). The virtual prototype visualizes quite a conventional tram cockpit but for the purposes of the project, it has been enhanced with the proposed new SmartTram features and control panels. The tram driver may now experience how it would be to operate a tram enhanced with advanced automatic features. In building the VR simulator as realistic as possible, the results of an earlier research study and interviews with conventional tram drivers was used to become acquainted with the context and the challenging situations faced in tram drivers' daily work. For example, the tram drivers described especially challenging the demand to react on the sudden movements of the pedestrians, cars or other trams ahead. In addition, maintaining the planned tram schedule, and maintaining the speed and adjusting it according to the varying breaking distance in different weather conditions was mentioned operations requiring skills and experience. The SmartTram simulator system was build based on this contextual understanding of the work of the tram drivers and the VR simulator was aimed at depict the tram driving conditions as realistically as 
IADIS International Journal on Computer Science and Information Systems

possible. Consequently, the VR simulator offers a high fidelity simulator environment that can be used for iterative design and evaluation of the SmartTram concept. The simulator platform is expected to be especially beneficial in involving and interacting with the expert users (i.e., tram drivers).

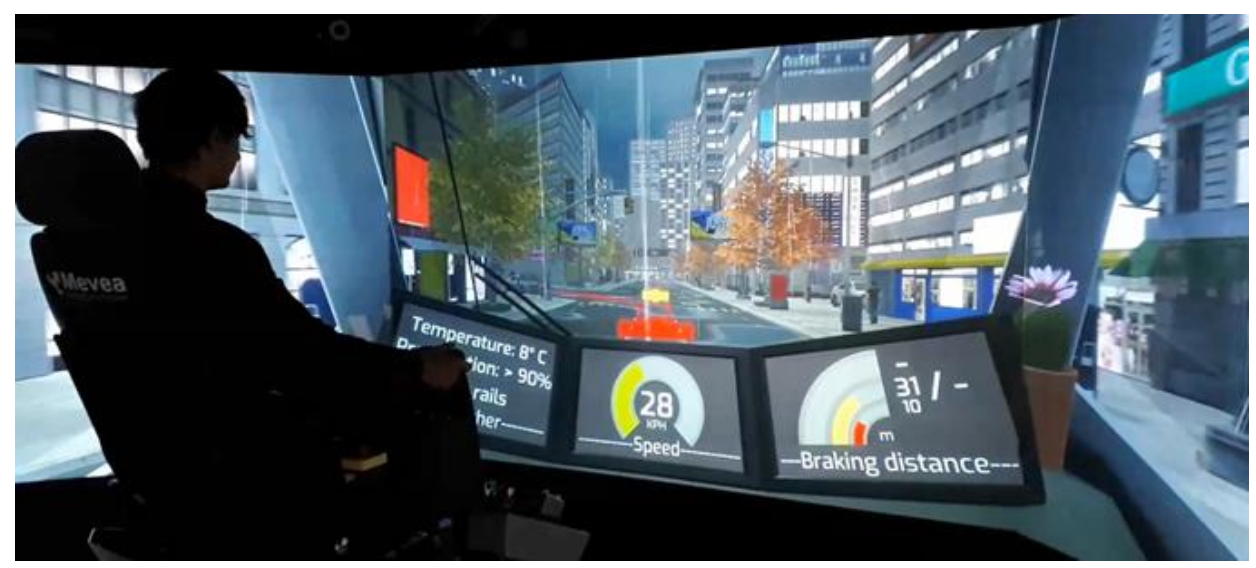

Figure 2. A virtual reality based SmartTram simulator. Tram operator's view in an autumn-evening lighting condition in an urban city environment. The rain and fallen leaves on the tramlines affect acceleration and stopping distance of the tram

The SmartTram simulator system includes 3D models of a tram and a city, road event visualizations (other trams, cars, pedestrians, etc.), different weather conditions (e.g., summer, autumn and winter specific circumstances such as high or low intensity of sunlight and slippery tramlines) and a new SmartTram visual-assistance system. The SmartTram visual-assistance system is based on the three main components: 1) precise physical model of the tramlines for the current route (e.g., all the turns and altitude changes), 2) tram localization on the route (i.e., GPS/ sensors on the track), and 3) self-awareness system similar to the ones used in the self-driving cars (including sensors for obstacle detection, braking performance calculations, environment conditions monitoring etc.). For example, related to the driving situation in autumn visualized in Figure 2, the SmartTram visual-assistance system is aware of the temperature, humidity and the tramline conditions (e.g., wet). The SmartTram system also uses computer vision to detect presence of leaves on the rails and by using above information, the SmartTram concludes that the rails are very slippery. Consequently, depending on the set level of automation, the SmartTram may notify or if needed even transfer the full control of the driving to the tram driver that may handle the difficult driving situation. Even though the human operator would not have any more the main responsibility of operative driving of the tram, it would still be necessary to have the human-in-the-loop at operating the tram system. In representing information to support human operator's situation awareness about the slippery trail conditions, the SmartTram visual-assistance system could, for example change color of the rails and display warning signs on the road surface to indicate the hazard. Similarly, the system may modify corner speed limits or form braking distance estimations, and visualize these for the tram driver. Consequently, the tram driver would then be better aware of the prevailing driving situation and thus be better prepared to take over the control if needed. Making design decisions on the level of automation and the different visualizations, human-system interaction 
concepts and the different automatic functionalities of the SmartTram may benefit greatly from the possibility to study and explore the qualities of different design solutions together with the users beforehand in a safe simulator environment.

In addition, two hazardous traffic situations (i.e., pedestrians running across the street unexpectedly and a car stopping in front of the tram) were initially introduced in the SmartTram simulator in order to be able to create realistic and challenging test scenarios. Through the scenarios that are based on possible real-life traffic situations in tram driving, it would be also possible to carry out more formal evaluations (e.g., ISV) about the interaction between the human operator and the automatic tram (i.e., the new concept of operation) when the design project is approaching to its end point. A realistic simulator environment is also essential in training the new tram drivers as the imagined role of human operator in operation of SmartTram is substantially different from the role that the dram drivers have today. The build SmartTram simulator system also includes data collection features (e.g., total time, collisions and stopping distance from the tram stop) which are useful when collecting evidence and evaluating the system with the users.

\section{DISCUSSION}

The SmartTram project face a challenge of developing an automatic tram that should become part of an infrastructure, which is already having an installed base (Bowker \& Start, 1999). Thus, an automatic tram will not be operating as a closed system but in an open environment and, that sets certain restrictions for the design. There may be many dependencies between the SmartTram system and other systems within the context of public transportation (e.g., traffic monitoring, shared stations/stops and sale of tickets) not to talk about the other services that constitute the smart city. The existing infrastructure and the fact that in the operating environment many issues are outside the decision power of the SmartTram project requires creating a proper contextual understanding that the design of automatic tram can be based on. Moreover, the safety-critical nature of the SmartTram as an automatic transport solution additionally challenge its development. Therefore, testing the technical system in isolation from its larger operational and social context of use would most likely lead to a failure.

It has been suggested that the failures in delivering successful outcomes in many large-scale development projects may be because of the lack of proper socio-technical understanding (Mumford, 2006). This has for one's part increase the pressure on these development projects for handling also the human and social aspects in design appropriately. Another aspect that speak for giving attention to the users early on is the well-known cost curve of design decisions (e.g., Verganti, 2009), that is to say, when the design process proceeds to its later phases making design changes become more costly. Providing again one more reason why the human and social aspects should be integrated into the design from the beginning. For example, in an early user study within the design of automatic container handling many critical piece of information affecting to the design decisions was found out when the crane operators were interviewed and their work observed in the field at the beginning of the project (Koskinen et al., 2013). The elicit user feedback in the study concerned, for example, the important angles of views (that aid design optimal placement of the cameras on the crane's body) and the "hidden" operating practices that aimed at anticipating and optimizing the operations not just as for one crane operator's part but from the overall operation point of view of the whole port. In the same vein, the relevant user 
IADIS International Journal on Computer Science and Information Systems

groups have been identified in the SmartTram project and a HFE program including the points of user interactions prepared in order to integrate the users' views and knowledge into the development. It is expected that, for example, the tram drivers' views and perceptions may be beneficial in order to set the suitable level of automation and define the final concept of operations in the Requirement and concept design phase. Before making these bigger conceptual decisions the more precise user requirements cannot be elicit. Moreover, in order to make the automatic tram operation safe in an urban city environment the other road users' perspectives should be inquired. In the concept phase, there is a need to define how the automatic tram is in interaction with its surrounding, for example, indicate for the pedestrians that it is safe to go over the crosswalk. All these are design decisions that in the end may affect the success of the project and how well the automatic tram is perceived by the public.

The availability of a virtual environment that can be used for user interaction and the iterative evaluation (i.e., V\&V) of the automatic tram solution is essential for the SmartTram project. It enables at the beginning of the project implementation of explorative user studies in which different user groups may experience the proposed future functionalities and provide formative design feedback. Whereas when proceeding to the end of the design process the virtual environment may be used for the summative evaluation of the integrated design solution, and thus as a safety-critical system fulfill the requirements of well-documented, independent and thorough validation of the functionality of the system.

\section{CONCLUSION}

In the modern smart city environments, many technologically advanced mobility services and solutions are expected to be in place. Thus, increasing levels of automation is also central in developing the public transportation. This paper describes development efforts to introduce automatic tram, that is, the SmartTram. The change from the conventional tram operation to the automatic operation is expected to bring many advances (e.g., efficiency and safety) but also some challenges (e.g., radical change in the human operator's role in driving the tram). Many complex and safety-critical design projects has suffered with lack of proper socio-technical understanding leading costly mistakes in later phases of the system operation. In the SmartTram project, the aim has been to integrate the human and social aspects in the design engineering from the very beginning of the development project. For this purpose, a dedicated HFE program with defined points of user interaction and a $\mathrm{V} \& \mathrm{~V}$ plan was introduced in the project.

In the following phases of our SmartTram project, the most critical HF activities are to set the user requirements and design an initial concept of operation for the SmartTram. Following the SUC approach, the initial goal structure will be formed to support the SmartTram V\&V process as well. Different user groups are intended to involve in the design and user studies should be conducted with the SmartTram simulator in order to refine the user requirements and validate the SmartTram operation concept. These activities in the Requirements and concept design phase will create a foundation for the later design phases of the development of SmartTram as well as enable monitoring that the SmartTram project is proceeding favorable direction also from the social and human point of view. Because, in the end, it begins from the smart 'integrative' design that can make the cities and the transport services of our future smart and sustainable. 


\section{ACKNOWLEDGEMENT}

We want to thank all researchers and partners in cooperation working within the SmartTram project and pursuing together towards a shared vision of well-functioning and safe traffic systems in smart cities. We also want to thank the interviewed tram drivers for sharing their valuable insights about their work.

\section{REFERENCES}

Balfour. A., Skorupka, A., Turzynska, D., 2012. Participatory Design and Human Factors within the Norwegian Oil and Gas Industry. Proceedings of Participatory Design Conference (PDC). Roskilde, Denmark, pp. 129-133. https://doi.org/10.1145/2348144.2348186

Bano, M \& Zowghi, D., 2015. A Systemic review on the relationship between user involvement and system success. Information and Software Technology, 58, pp. 148-169.

Beiker, S., 2014. Road Vehicle Automation. Road Vehicle Automation, January, 61-70. https://doi.org/10.1007/978-3-319-05990-7

Bishop, P., \& Bloomfield, R. A. (1998). Methodology for Safety Case Development. Proceedings of Safety-Critical Systems Symposium.

Bowker, GC. \& Star, S., 1999. Sorting thingsout: Classification and itse consequenses. MIT Press.

Bødker, S. \& Pekkola, S., 2010. A short review to the past and present of participatory design. Scandinavian Journal of Information Systems, pp. 45-48.

Cohen, T., Jones, P., \& Cavoli, C. C., 2017. Social and behavioural questions associated with automated vehicles: scoping study: final report. January, pp. 1-124.

EPRI, 2004HumanFactors Guidance for Contro Room and Digital Human-System Interface Design and Modification - Guidelines for Planning, Specification, Design, Licensing, Implementation, Training, Operation, and Maintenance. Electric Power Research Instritute, EPRI 1008122, November.

Hale, A., Kirwan, B., \& Kjellén, U., 2007. Safe by design: where are we now? Safety Science, 45, $305-327$.

Hofmann, M., 2020. Siemens Mobility and Transport Company VIP Postdam: On the path to an autonomous tram. Bahn Manager Magazin.

Hugo, J., 2000. Towards a unified HFE process for the nuclear industry. Proceedings of NPIC\& HMIT. San Diego, CA.

Hulse, L. M., Xie, H., \& Galea, E. R., 2018. Perceptions of autonomous vehicles : Relationships with road users, risk, gender and age. Safety Science, 102(April 2017), pp. 1-13. https://doi.org/10.1016/j.ssci.2017.10.001

Johannessen, L. \& Ellingsen, G., 2008. Lightweight methods in heavyweight organizations. Proceedings of the tenth Anniversary Conference on Participatory Design. pp.11-20

Karvonen, H., Aaltonen, I., Wahlström, M., Salo, L., Savioja, P., \& Norros, L, 2011. Hidden roles of the train driver: A challenge for metro automation. Interacting with Computers, 23(4), pp. 289-298. https://doi.org/10.1016/j.intcom.2011.04.008

Koskinen, H., Karvonen, H., Haggren, J., 2012. Enhancing the User Experience of the Crane Operator: Comparing Work Demands in Two Operational Settings. Proceedings of the 30st European Conference on Cognitive Ergonomics, Edinburgh, United Kingdom pp.37-44

Koskinen, H., Laarni, J., Liinasuo, M., Norros, L., \& Savioja, P, 2021. Systems Usability Case in Stepwise Control Room Validation. Safety Science 134, December 2019: 105030. https://doi.org/10.1016/j.ssci.2020.105030 
IADIS International Journal on Computer Science and Information Systems

Kujala, S., 2003. User Involvement: a review of the benefits and challenges, Behav. Inform. Technol. 22, pp.1-16.

Kyriakidis, M., de Winter, J. C. F., Stanton, N., Bellet, T., van Arem, B., Brookhuis, K., Martens, M. H., Bengler, K., Andersson, J., Merat, N., Reed, N., Flament, M., Hagenzieker, M., \& Happee, R. 2019. A human factors perspective on automated driving. Theoretical Issues in Ergonomics Science, 20(3), pp. 223-249. https://doi.org/10.1080/1463922X.2017.1293187

Laarni, J., Savioja, P., Norros, L., Liinasuo, M., Wahlström, M., \& Salo, L. 2014. Conducting multistage HFE validations - constructing Systems Usability Case. Proceedings of ISOFIC/ISSNP 2014, pp.1-10.

Liinasuo, M., \& Norros, L. 2007. Usability case - integrating usability evaluations in design. In E. Law, K. Larusdottir, \& M. Norgaard (Eds.), COST294-MAUSE Workshop on Downstream Utility. Institute of Research in Informatics of Toulouse IRIT.

Merat, N., \& Jamson, A. H., 2009. How Do Drivers Behave in a Highly Automated Car? Proceedings of Driving Assesment Conference, pp.514-521.

Money, A., Barnett, J., Kuljis, J., 2011. The role of the user within the medical device design and development process: Medical device manufacturers' perspective. BMC Medical Informatics and Decision making, 11(1).

Mumford, E., 2006. The story of socio-technical design: reclections in its successes, failures and potential. Information System Journal, Vol 16, pp. 317-342.

Norros, L., 2004. Acting under Uncertainty: The core-Task Analysis in Ecological Study of Work. VTT publications, Espoo, Finland

NUREG-0711, 2012. Human Factors Engineering Program Review Model. United States Nuclear Regulatory Commission, Washington, D.C.

Parkin, J., Clark, B., Clayton, W., Ricci, M., \& Parkhurst, G. 2016. Understanding interactions between autonomous vehicles and other road users: A Literature Review.

Rasouli, A., \& Tsotsos, J., 2018. Autonomous Vehicles that Interact with Pedestrians A Survey of Theory and Practice. THE IEEE TRANSACTIONS ON INTELLIGENT TRANSPORTATION SYSTEMS.

SAE, 2018. Surface vehicle recommended practice; taxonomy and definitions for terms related to driving autonation systems for on-road motor vehicles. SAE International, pp. 1-35.

Savioja, P., 2014. Evaluating Systems Usability in Complex Work: Deeloping of a Systemic Usability Concept to Benefit Control Room Design. Aalto University.

Verganti, R. 2009. Design-Driven Innovation. Boston, MA: Harvard Business Press.

Wahlström, M., Karvonen, H., Kaasinen, E., \& Mannonen, P., 2016. Designing user-oriented future ship bridges: An approach for radical concept design. Ergonomics in Design: Methods and Techniques, August, 219-233. https://doi.org/10.1201/9781315367668 